\title{
Microwave irradiated synthesis and characterization of 1, 4-phenylene bis-oxazoline form bis-(2-hydroxyethyl) terephthalamide obtained by depolymerization of poly (ethylene terephthalate) (PET) bottle wastes
}

\author{
Yogesh S. Parab, Rikhil V. Shah and Sanjeev R. Shukla*
}

Department of Fibres and Textile Processing Technology, Institute of Chemical Technology, University under Section- 3 of UGC act 1956, Matunga, Mumbai- 400019, India

\begin{tabular}{l}
\hline A R T I C L E I N F O \\
\hline Article history: \\
Received February 08, 2012 \\
Received in Revised form \\
Feb 19, 2011 \\
Accepted 10 March 2011 \\
Available online \\
31 March 2012 \\
\hline Keywords: \\
PET bottle waste \\
Depolymerization \\
Beta-zeolite \\
Montmorillonite KSF \\
2,2-(1,4-Phenylene)bis(2- \\
oxazoline)
\end{tabular}

\begin{abstract}
A B S T R A C T
The aminolytic depolymerization of PET bottle waste with ethanolamine by conventional heating and microwave irradiation heating method was attempted with heterogeneous, recyclable acid catalysts such as beta zeolite $(\mathrm{SiO} 2 / \mathrm{AlO} 2=15 \mathrm{Na}-$ form $)$ and montmorillonite KSF. The pure product bis-(2-hydroxyethyl) terephthalamide (BHETA) of aminolysis was obtained in good yield (85- 88\%). The BHETA, thus obtained, was subjected to cyclization reaction by heating with polyphosphoric acid as well as by chlorination (using phosphoryl chloride), bromination (using red phosphorous and liquid bromine) and nitration (conc. HNO3 + conc. $\mathrm{H} 2 \mathrm{SO} 4$ ) followed by conventional and microwave irradiation heating in $\mathrm{N}, \mathrm{N}$ - dimethyl formamide/ potassium carbonate solution. The product so obtained was 2, 2'-(1,4-phenylene)bis-(2-oxazoline) (PBO), which has applications in polymer synthesis as a chain extender/ chain coupling agent or a cross linker. The productswere analyzed by FTIR, DSC, Mass and NMR (1H and 13C NMR).
\end{abstract}

\section{Introduction}

Recent global concerns about environment are focused on development of recycling technologies for waste plastics ${ }^{1}$. Poly (ethylene terephthalate) (PET) is one of the versatile engineering plastics with excellent thermal and mechanical properties. It is semi-crystalline, non- toxic polyester with high strength and transparency, by virtue of which large quantities are used in the manufacture of food packaging and especially of soft drink bottles. 
The substantial contribution of PET in solid waste generation and its high resistance to degradative assimilation into the environment labels it as a noxious material. Recycling of PET contributes to the conservation of raw petrochemical products and of energy to the tune of 50-60\% as compared to making the same product from virgin resin. Solvolytic chain cleavage of PET is possible by reagents, such as water (hydrolysis), alcohols (alcoholysis), amines (aminolysis), acids (acidolysis) leading to a large variety of valuable products ${ }^{2}$.

Aminolysis of PET has been carried out using different amines such as allyl amine ${ }^{3}$, alkyl amine 4 , morpholine, hydrazine hydrate ${ }^{5}$, polyamines and triethanolamine ${ }^{6,7}$. Earlier in our laboratory, PET has been depolymerized by ethanolamine using simple chemicals as catalysts such as sodium acetate, glacial acetic acid, potassium sulfate and sodium bicarbonate under reflux with conventional heating for $8 \mathrm{~h}$ and under microwave heating for $7 \mathrm{~min}$ to get the virtual monomer bis (2-hydroxyethyl) terephthalamide (BHETA) ${ }^{8,9}$ with about $86 \%$ yield comparable with that obtained using the conventional lead or zinc acetate catalysts, which are in the category of heavy metals.

In recent years, the use of heterogeneous inorganic solid acidic catalysts has received considerable attention in different areas of organic synthesis because of their environmental compatibility, high selectivity, operational simplicity, non-corrosiveness and low cost ${ }^{10}$ a-c The heterogeneous catalysts/ clay minerals like zeolites can catalyze a variety of organic reactions occurring on their surface and interstitial spaces. Structurally, zeolites are porous crystalline hydrous alumino-silicates built from $\mathrm{SiO}_{4}$ and $\mathrm{AlO}_{4}$ tetrahedral frameworks. In zeolite structure, $\mathrm{Si}^{4+}$ and $\mathrm{Al}^{3+}$ atoms are tetra coordinated, shared with oxide ions. This feature develops a negative charge on the aluminum atom and demands the existence of counter-ion outside the framework to reach neutrality of the crystalline structure. When protons $\left(\mathrm{H}^{+}\right)$are used, these materials act as Bronsted acids. Such zwitter ionic character is responsible for the unique chemistry of these materials. Zeolites find major uses in petroleum cracking, ion-exchange (water softening and purification), and in the separation and removal of gases and solvents ${ }^{11}$. They have been effectively used for aminolysis of esters by Ogava et al. ${ }^{12}$

Using clay catalysts, environmentally benign green chemistry can be adopted both at laboratory scale and industrial level. In the last few years a growing interest has also been shown in the use of microwave irradiation in organic synthesis 13,14 . Montmorillonite clays have been used as solid inorganic acid catalysts for number of organic reactions and offer several advantages over classical acids in terms of strong acidity, non-corrosive properties, cheapness, reusability/ regenerablity, mild reaction conditions, high yields and selectivity, and the ease of set-up and work-up ${ }^{15}$. It,s lattice is composed of a sheet of octahedrally coordinated gibbsite $\left[\mathrm{Al}_{2}(\mathrm{OH})_{6}\right]$ sandwiched between two sheets of tetrahedrally coordinated silicate $[\mathrm{SiO} 4]^{4-}$ sheets, the three- sheet layer repeats itself, and the interlayer space holds the key to the chemical and the physical properties of the clay. The Bronsted acid character of clays arises mainly due to the dissociation of the intercalated water molecules coordinated to cations (equation 1).

$\left[\mathrm{M}\left(\mathrm{H}_{2} \mathrm{O}\right)_{\mathrm{n}}\right]^{3+} \longrightarrow\left[\mathrm{M}\left(\mathrm{H}_{2} \mathrm{O}\right)_{\mathrm{n}-1} \mathrm{OH}\right]^{2+}+\mathbf{H}^{+}$

The unique and highly useful cyclic imino ethers (classified as cyclic endo- and cyclic exo-) commonly called as oxazoline. These bisoxazoline monomers are very useful as chain extenders or cross linking agents in building polymeric structures. ${ }^{[16-18]}$ In literature ${ }^{19-21} 1$, 4- phenylene bis(oxazoline) has been reported to be prepared from nitriles and alkanolamine, in the presence of catalytic amounts of a moderate Lewis acid or also from halo amides ${ }^{22-25}$, using strong base such as potassium fluoride on solid support ${ }^{26}$. Also, the reaction of carboxylic acids with amino alcohols is the most common method for the synthesis of oxazoline ${ }^{27-30}$. The limitations associated with these methods are however, that the direct conversion of carboxylic acids into the corresponding 2oxazolines proceed with elimination of water at high temperatures $\left(160-220{ }^{\circ} \mathrm{C}\right)$, requiring long reaction times $\left(12-18 \mathrm{~h}\right.$ ) and giving low yields frequently ${ }^{31,32}$. Also, the use of nitriles requires a 
Lewis acid and proceeds at high temperatures with elimination of ammonia ${ }^{33}$.Other methods utilize complex reagents ${ }^{34,35}$ or strongly acidic conditions ${ }^{36}$.

The present work reports the results on degradation of PET bottle wastes by using heterogeneous acid catalysts such as beta-zeolite and montmorillonite KSF under conventional and microwave heating. The pure BHETA obtained was then subjected to the synthesis of 2,2'-(1,4-phenylene)-bis(2oxazoline) (PBO) by two different routes of cyclization. The products, BHETA and PBO, were characterized with the help of FTIR, DSC, Mass and NMR $\left({ }^{1} \mathrm{H}\right.$ and ${ }^{13} \mathrm{C}$ NMR $)$. PBO finds application in polymer synthesis as a chain extender/ chain coupling agent or a cross linker.

\section{Results and discussion}

Scheme 1, represents the depolymerization of PET using ethanolamine to obtained monomer BHETA. The depolymerization conditions have been optimized through various parameters such as aminolysis time, catalyst concentration, PET: ethanolamine ratio to get maximum possible yield of pure product. Whereas, scheme 2 shows the synthesis of important heterocycles PBO from two methods, first one is two step synthesis through intermediate formation (BHETA-Cl, BHETA-Br, BHETA-NO2) and other is, one step direct synthesis from BHETA.

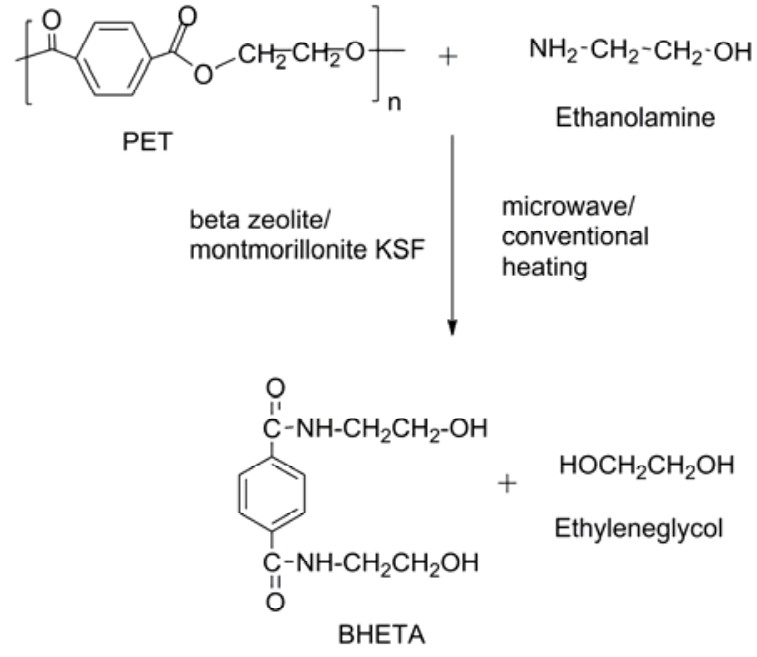

Scheme 1: Aminolytic depolymerization of PET using ethanolamine

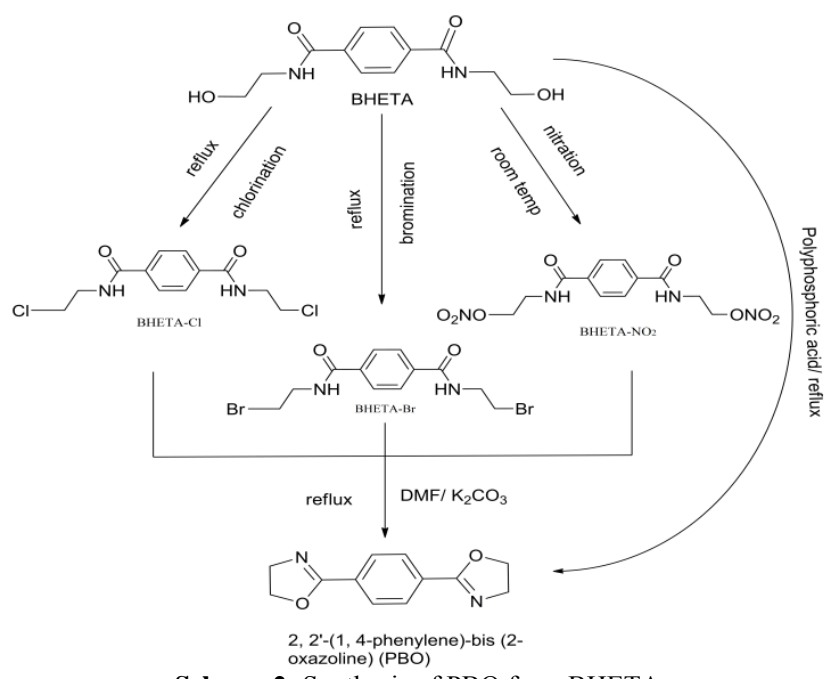

Scheme 2: Synthesis of PBO from BHETA

Table 1 show that $4 \mathrm{~h}$ is the optimum time for aminolytic depolymerization of PET bottle waste to get maximum yield of BHETA. The yields obtained using beta- zeolite and montmorillonite KSF catalysts were nearly same (85- $86 \%$ ). Further, when the aminolysis was carried out under microwave heating, the time required for similar yields (86- $88 \%$ ) of BHETA was as low as 5- 6 $\min$.

Table 1. Effect of depolymerization time on BHETA yield (\%)

\begin{tabular}{|c|c|c|c|c|}
\hline \multirow{3}{*}{ Time } & \multicolumn{4}{|c|}{ BHETA yields (\%) } \\
\hline & \multicolumn{2}{|c|}{ Conventional heating } & \multicolumn{2}{|c|}{ Microwave heating } \\
\hline & Beta-zeolire & Montmorillonite KSF & Beta-zeolire & Montmorillonite KSF \\
\hline $1 \mathrm{~h}$ & 57 & 58 & - & - \\
\hline $2 \mathrm{~h}$ & 66 & 65 & - & - \\
\hline $3 \mathrm{~h}$ & 75 & 76 & - & - \\
\hline $4 h$ & 85 & 86 & - & - \\
\hline $5 \mathrm{~h}$ & 85 & 85 & - & - \\
\hline $6 \mathrm{~h}$ & 86 & 85 & - & - \\
\hline $3 \mathrm{~min}$ & - & - & 64 & 67 \\
\hline $4 \mathrm{~min}$ & - & - & 73 & 79 \\
\hline $5 \mathrm{~min}$ & - & - & 87 & 88 \\
\hline $7 \mathrm{~min}$ & - & - & 87 & 88 \\
\hline $8 \mathrm{~min}$ & - & - & 86 & 87 \\
\hline
\end{tabular}

PET: ethanolamine: 1:6, Catalyst concentration: $1 \% \mathrm{w} / \mathrm{w}$ for beta zeolite and $0.5 \% \mathrm{w} / \mathrm{w}$ for montmorillonite KSF 
With increase in the beta zeolite concentration upto $1 \% \mathrm{w} / \mathrm{w}$ of PET, the yield of BHETA increased irrespective of the mode of heating. Montmorillonite KSF, however, was required only 0.5 $\% \mathrm{w} / \mathrm{w}$ of PET and the corresponding yield obtained was $85-88 \%$ in either form of heating (Table 2).

Table 2. Effect of catalyst concentration on BHETA yield

\begin{tabular}{ccccc}
\hline \multirow{2}{*}{$\begin{array}{c}\text { Catalyst Concentration } \\
\text { \% (w/w) }\end{array}$} & \multicolumn{3}{c}{ Conventional heating } & \multicolumn{2}{c}{ Microwave heating } \\
\cline { 2 - 5 } & Beta zeolite & Montmorillonite KSF & Beta zeolite & Montmorillonite KSF \\
\hline 0.2 & 39 & 62 & 48 & 72 \\
0.4 & 52 & 73 & 57 & 81 \\
0.5 & 64 & 86 & 68 & 88 \\
0.6 & 70 & 86 & 74 & - \\
0.8 & 78 & - & 81 & - \\
1.0 & 85 & - & 87 & - \\
1.2 & 85 & - & 87 & \\
\hline
\end{tabular}

Time was selected on the basis of optimum yield as indicated in Table 1 PET: Ethanolamine :: 1:6

When PET: ethanolamine ratio was varied from 1: 2 to 1: 8 (Table 3), the yield of BHETA was found to be maximum at 1: 6:: PET: ethanolamine ratio i.e. $85-88 \%$, which remained almost constant thereafter.

Table 3: Effect of PET: Ethanolamine ratio on BHETA yield

\begin{tabular}{ccccc}
\hline \multirow{2}{*}{$\begin{array}{c}\text { Catalyst Concentration } \\
\text { \% }(\mathrm{w} / \mathrm{w})\end{array}$} & \multicolumn{2}{c}{ Conventional heating } & \multicolumn{2}{c}{ Microwave heating } \\
\cline { 2 - 5 } & Beta zeolite & Montmorillonite KSF & Beta zeolite & Montmorillonite KSF \\
\hline $1: 2$ & 48 & 51 & 49 & 55 \\
$1: 4$ & 67 & 71 & 68 & 74 \\
$\mathbf{1 : 6}$ & $\mathbf{8 5}$ & $\mathbf{8 6}$ & $\mathbf{8 7}$ & $\mathbf{8 8}$ \\
$1: 8$ & 82 & 84 & 85 & 85 \\
\hline Time was selected on the basis of optimum yield as indicated in Table 1 Catalyst concentration: $1 \%(w / w)$ for beta zeolite and $0.5 \%(w / w)$ for \\
montmorillonite KSF
\end{tabular}

Thus, beta zeolite and montmorillonite KSF reduced the depolymerization time to $4 \mathrm{~h}$ when compared with conventional heavy metal acetate and other simple chemicals as catalysts which required $8 \mathrm{~h}$ for similar PET depolymerization ${ }^{8}$. Also, the microwave assisted depolymerization reduced the time of reaction significantly.

\section{Conclusions}

Aminolytic depolymerization of PET with ethanolamine by conventional heating and under microwave irradiation using natural and environmentally safe heterogeneous solid inorganic acid aluminosilicate catalysts such as beta-zeolite and montmorillonite KSF was investigated. Microwave irradiation was more efficient energy source requiring significantly short depolymerization time, without affecting the yield (85- $88 \%$ ) of pure product, BHETA. The conservation in time and energy of reaction coupled with substitution of heavy metal catalysts by simple, recyclable, non-toxic and cheap catalysts makes the process convenient, more economic and benign. PBO, which is quite useful in polymer chemistry as chain extender or cross linker has been synthesized from BHETA by cyclization in one step using different methods. Thus, the results lead to much sought after environmentally safe process of PET waste depolymerization into pure BHETA and PBO synthesis there from.

\section{Acknowledgements}

The authors acknowledge the financial support received from the Council of Scientific and Industrial Research (CSIR), New Delhi, India. 


\section{Experimental}

\subsection{Materials and Methods}

\section{Materials}

Discarded PET soft drink bottles were obtained from a local market, cut into small pieces of approximate size $5 \times 5 \mathrm{~mm}$ after separating from the non- PET components such as labels and caps. They were cleaned by boiling with a solution containing $2 \mathrm{~g} / \mathrm{L}$ of a detergent for $1 \mathrm{~h}$ followed by thorough washing with water and drying in air.

\section{Chemicals}

Beta-Zeolite $\mathrm{Na}$ form $\left(\mathrm{SiO}_{2} / \mathrm{AlO}_{2}\right.$ ratio $\left.=15\right)$ powder and montmorillonite $\mathrm{KSF}$ were used as catalysts and were obtained from Sub- Chemie (Mumbai, India) Ltd. Ethanolamine, phosphoryl chloride, N, N- dimethyl formamide, potassium carbonate, sodium carbonate, red phosphorous, polyphosphoric acid, liquid bromine, conc. nitric acid and conc. sulfuric acid obtained from Merck (Mumbai, India) Ltd. were all of analytical reagent (AR) grade.

\section{General procedure}

\section{Aminolysis of polyester waste}

\section{a. Aminolysis of PET waste under conventional heating}

Ethanolamine was used for the aminolysis of PET waste (PET: ethanolamine :: 1: 6) under reflux in the presence of heterogeneous catalysts such as beta-zeolite/ montmorillonite KSF for time periods varying up to $6 \mathrm{~h}$. The catalyst concentration was varied between $0.2 \%$ and $1.2 \%$ by weight of PET. At the end of the reaction, distilled water was added in excess to the reaction mixture with vigorous agitation to precipitate out the product [bis (2- hydroxy ethylene) terephthalamide]. The precipitate obtained was filtered and dissolved in distilled water by boiling. White crystals of (BHETA) were obtained by first concentrating the filtrate by boiling and then chilling it. It was purified by repeated crystallization from water, dried in an oven at $70{ }^{\circ} \mathrm{C}$ and weighed for estimating the yield.

\section{b. Aminolysis of PET waste under microwave heating}

Aminolysis of PET waste was carried out in a $700 \mathrm{~W}$ Electrolux (Mumbai, India) (17 L) domestic microwave oven. It was modified to allow fitting of a condenser as described in the previous communication ${ }^{37}$. The PET waste was treated with ethanolamine under reflux using microwave oven at maximum power with conditions same as in conventional methods, except that the time was varied up to $8 \mathrm{~min}$. Rest of the procedure for obtaining the product, BHETA, was also the same as given for conventional methods.

Synthesis of 2, 2'- (1, 4- phenylene) - bis (2- oxazoline) (PBO) from BHETA:

a. One step PBO synthesis from BHETA using poly phosphoric acid:

To polyphosphoric acid $(5 \mathrm{ml}), 1 \mathrm{~g}$ of BHETA was added and refluxed it for $3 \mathrm{~h}$. After the completion of reaction, the reaction mass was cooled to room temperature and diluted with cold water. It was then neutralized with $5 \%$ sodium bicarbonate solution to obtain the crude product, which was filtered, washed with water, recrystallized by DMF- water mixture and dried in vacuum oven at $80{ }^{\circ} \mathrm{C}$. The pure product, thus obtained, was confirmed by FTIR, DSC, NMR and melting point characterization to be PBO (yield $72 \%$ ).

\section{b. Two step PBO synthesis from BCIETA, BBrETA and $\mathrm{BNO}_{2} E T A$ :}




\section{I (a) Preparation of bis (2- chloro ethyl terephthalamide) (BCIETA):}

To a solution of BHETA $(1 \mathrm{~g})$ in $8-10 \mathrm{ml}$ of methylene chloride, phosphoryl chloride $(1 \mathrm{ml})$ was added drop wise at $0-5{ }^{0} \mathrm{C}$ and stirred the reaction mass for about $1 \mathrm{~h}$ at room temperature. Clear solution was obtained and completion of the reaction was checked by TLC. The reaction mass was cooled to $5-10{ }^{\circ} \mathrm{C}$ and neutralized with $5 \%$ sodium bicarbonate solution. The product was filtered, washed and recrystallized from water and dried in vacuum to give white crystalline powder. It was characterized by FTIR, DSC and NMR and was found to be bis (2- chloro ethylene) terephthalamide (BClETA) (yield $81 \%$ ).

\section{(b) Preparation of bis (2- bromo ethyl terephthalamide) (BBrETA):}

Accurately weighed BHETA ( $1 \mathrm{~g})$ and red phosphorus $(0.3 \mathrm{~g})$ was dissolved in DMF and taken in a three necked round bottom flask fitted with a dropping funnel, stirrer and condenser. Accurately weighed bromine $(1.5 \mathrm{ml})$ was taken in a dropping funnel to facilitate its addition in a continuous drop-wise manner. After completion of the reaction, reaction mass was poured into ice water and then neutralized it with saturated sodium bicarbonate solution. It was then filtered, washed and recrystallized from chloroform and dried in vacuum to give white crystalline powder. The product obtained was white solids of bis (2-bromo ethyl) terephthalamide confirmed by FTIR, DSC and NMR (yield $75 \%$ ).

\section{(c) Preparation of bis (2- nitro ethyl terephthalamide) (BNO $\mathrm{BNTA}_{2}$ :}

In a round bottom flask, $1 \mathrm{~g}$ of BHETA was dissolved in $5 \mathrm{ml}$ of concentrated sulfuric acid (dropwise), and chilled it in an ice bath. Continue to cool the mixture in the ice bath to reduce the heat produced during the reaction. Gradually $2 \mathrm{ml}$ of concentrated nitric acid was then added to it in a drop- wise manner. Reaction was continued till completion, checked by TLC. Then it was poured in cold water with stirring. Isolate the crude product by vacuum filtration and wash it with ice cold water. The crude material was then purified by recrystallization from acetone (yield $77 \%$ ). Finally bis (2- nitro ethyl terephthalamide) $\left(\mathrm{BNO}_{2} \mathrm{ETA}\right)$ was confirmed by FTIR, DSC and NMR.

$$
\text { PBO synthesis from BCIETA, BBrETA and } \mathrm{BNO}_{2} \text { ETA: }
$$

\section{(a) conventional heating:}

BClETA, BBrETA and $\mathrm{BNO}_{2}$ ETA $(1 \mathrm{~g})$ were further subjected to cyclization reaction by first dissolving in DMF $(5-7 \mathrm{ml})$ and then refluxing for $3 \mathrm{~h}$ in the presence of $\mathrm{K}_{2} \mathrm{CO}_{3}(2 \mathrm{~mol})$ as basic catalyst. After completion of reaction, the hot reaction mass was filtered, allowed to cool to room temperature, and then kept in refrigerator overnight. Pure, fine crystals were obtained which were then identified by FTIR, DSC, Mass and NMR analysis to be 2, 2'- (1, 4- Phenylene) - bis (2oxazoline) (PBO) (yield 75- $77 \%$ ).

\section{(b) microwave irradiation heating method :}

PBO synthesis was also carried out by microwave heating using the same assembly used for aminolysis of PET above. BCIETA, BBrETA and $\mathrm{BNO}_{2}$ ETA $(1 \mathrm{~g})$ were solublized in $(5-7 \mathrm{ml})$ DMF and $2 \mathrm{~mol}$ of $\mathrm{K}_{2} \mathrm{CO}_{3}$ was added to it and cyclization was carried out under reflux for $12 \mathrm{~min}$. Rest of the procedure for obtaining the pure product, $\mathrm{PBO}$, was the same as mentioned earlier (yield $79 \%$ ).

\section{Characterization of BHETA and PBO}

After purification through repeated crystallization, the products, BHETA and PBO, were characterized with the help of FTIR, DSC, Mass and NMR ( ${ }^{1} \mathrm{H}$ and ${ }^{13} \mathrm{C}$ NMR). 
FTIR spectrum were recorded on Shimadzu, Japan (Model 8400 S) FTIR spectrophotometer using ATR technique. The product was also characterized for its melting point with the help of Differential scanning calorimeter (DSC), (Shimadzu 60, Japan) at the heating rate of $10{ }^{\circ} \mathrm{C} / \mathrm{min}$ from $40{ }^{0} \mathrm{C}$ to $400{ }^{0} \mathrm{C}$ under nitrogen atmosphere. Mass spectra were measured on Thermo mass spectrometer by electron ionization. The aminolytic product obtained was also subjected to thin layer chromatography (TLC) analysis with ethanol: chloroform (2: 8) mixture as an eluent. For Nuclear Magnetic Resonance (proton and carbon NMR), the product after aminolysis reaction was dissolved in solvent d6- DMSO. Chemical shifts are expressed in $\delta$ units (ppm) using tetramethyl silane as an internal reference and the spectrograph was recorded on Bruker, NMR (300 MHz).

\section{FTIR spectral analysis}

Fig. 1 (a) shows the FTIR spectrum of the aminolyzed product BHETA. The peaks at 1052 and $3285 \mathrm{~cm}^{-1}$ indicate the presence of primary alcohol. The peak at $1319 \mathrm{~cm}^{-1}$ is due to $\mathrm{C}-\mathrm{N}$ stretching and peaks for secondary amide stretching are observed at 1558 and $3361 \mathrm{~cm}^{-1}$. The $\mathrm{C}=\mathrm{O}$ appears at $1623 \mathrm{~cm}^{-1}$. In the FTIR spectrogram for PBO Fig. 1 (b), the peak at $1637 \mathrm{~cm}^{-1}$ indicates the presence of $-\mathrm{C}=\mathrm{N}$ stretching. The peaks at $3361 \mathrm{~cm}^{-1}$ for secondary amide stretching and at $3285 \mathrm{~cm}^{-1}$ for $\mathrm{OH}$ primary alcohol have disappeared due to cyclization of BHETA monomer and formation of PBO. Other peaks observed at $3048 \mathrm{~cm}^{-1}$ and $2875-2970 \mathrm{~cm}^{-1}$ correspond to aromatic $-\mathrm{CH}$ protons and aliphatic $-\mathrm{CH}_{2}$ protons, respectively.

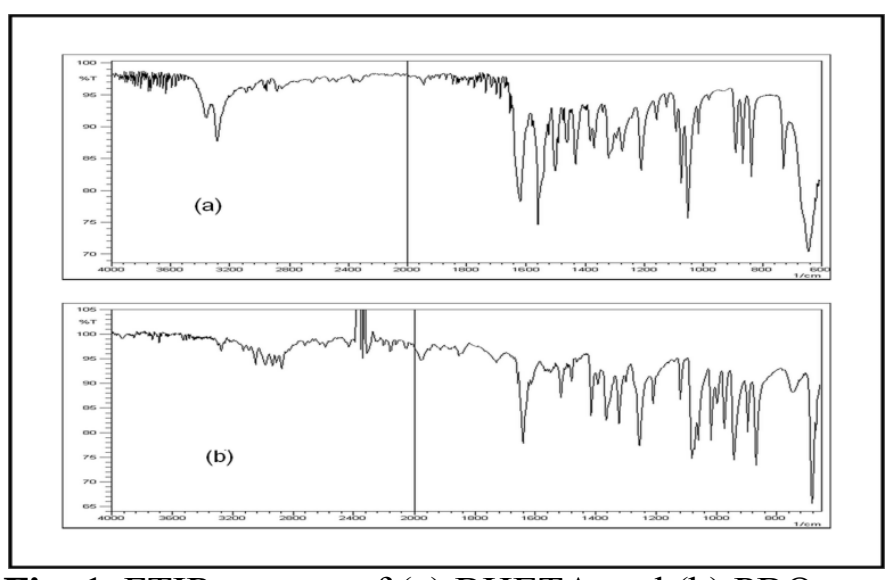

Fig. 1. FTIR spectra of (a) BHETA and (b) PBO

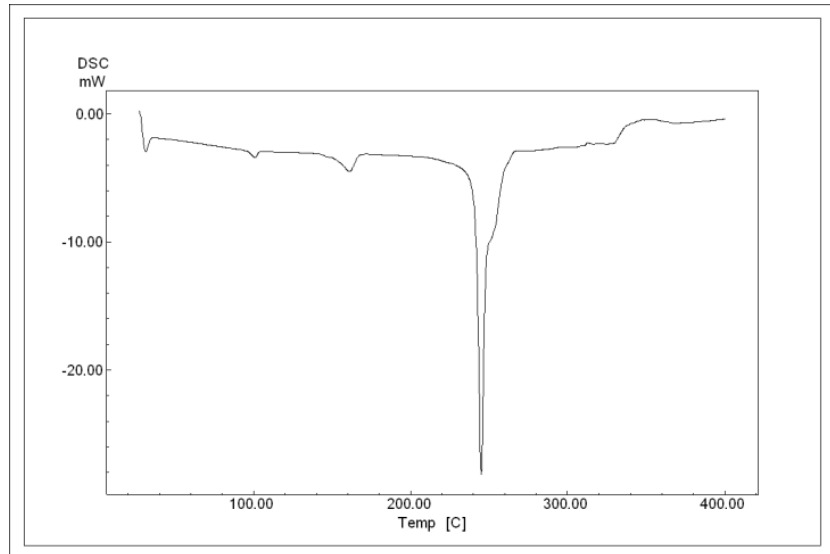

Fig. 2. DSC spectrum of PBO

\section{Thermal analysis (DSC)}

The DSC thermogram was recorded from $40{ }^{\circ} \mathrm{C}$ to $400{ }^{\circ} \mathrm{C}$ at a heating rate of $10{ }^{\circ} \mathrm{C}$ per minute under nitrogen atmosphere. Fig. 2 gives DSC scan of $\mathrm{PBO}$, which indicates that the melting point of the compound is $245{ }^{0} \mathrm{C}$ (lit. ${ }^{24}$, mp. $243-246{ }^{0} \mathrm{C}$ ).

\section{NMR analysis}

The ${ }^{1} \mathrm{H}$ NMR for the PBO Fig. 3 shows the peak in the region $\delta 4.47-4.38$ ppm corresponding to $\mathrm{CH}_{2}$ group protons attached to oxygen, peak in the region $\delta 4.03-3.93$ ppm corresponds to other $\mathrm{CH}_{2}$ group protons attached to nitrogen and at $\delta 7.97 \mathrm{ppm}$ corresponding to aromatic ring protons. ${ }^{13} \mathrm{C}$ NMR spectra of PBO Fig. 4 shows peak at $\delta 162.40 \mathrm{ppm}$ of the carbon attached to aromatic ring and the peaks at $\delta 129.91 \mathrm{ppm}$ and $127.96 \mathrm{ppm}$ corresponding to aromatic carbons. The peak at $\delta 67.58$ ppm relates to aliphatic carbon attached to the oxygen atom and peak at $\delta 54.56 \mathrm{ppm}$ is due to $\mathrm{CH}_{2}$ attached to nitrogen atom. 


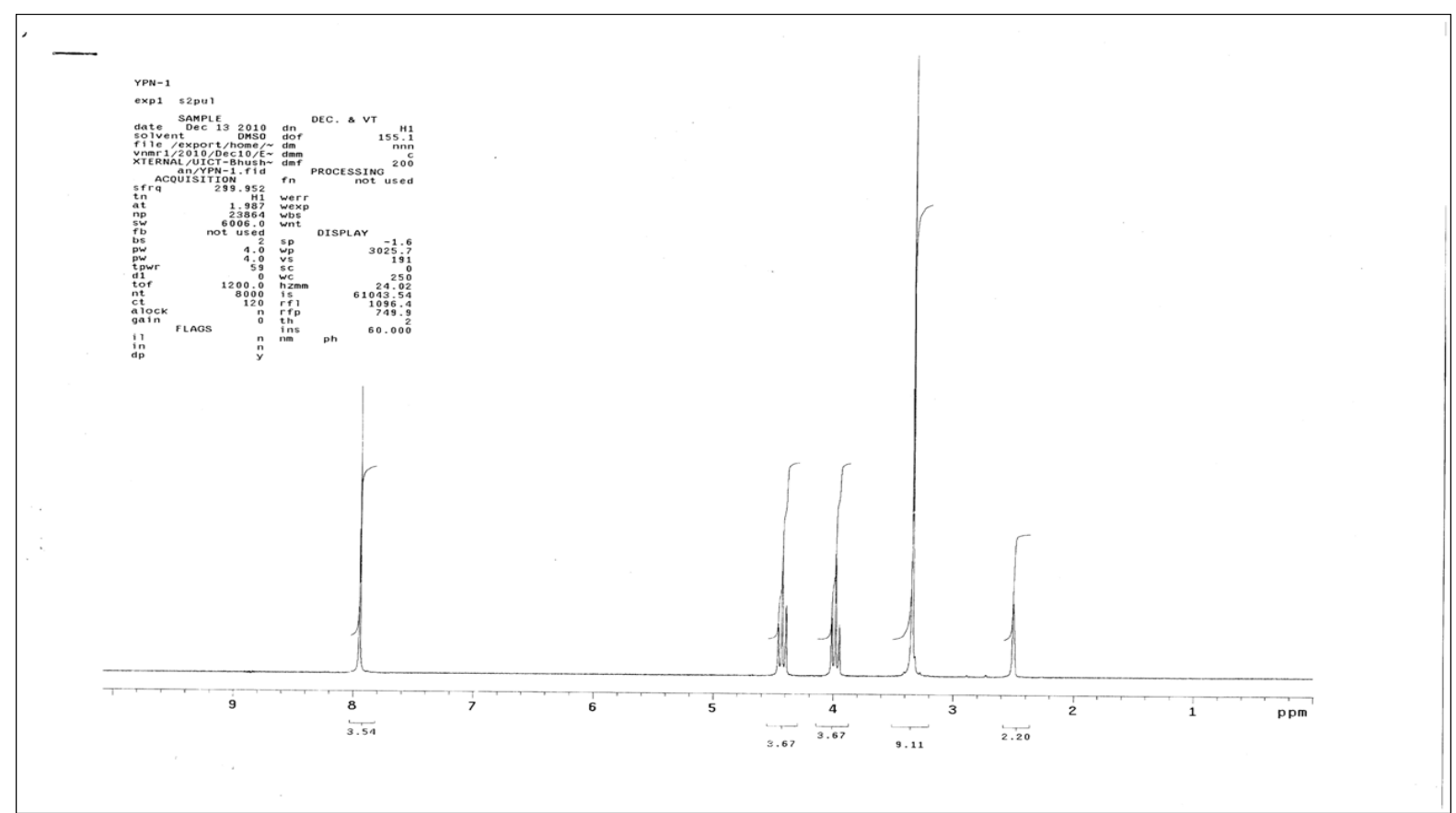

Fig. 3. ${ }^{1} \mathrm{H}-\mathrm{NMR}$ spectrum of $\mathrm{PBO}$

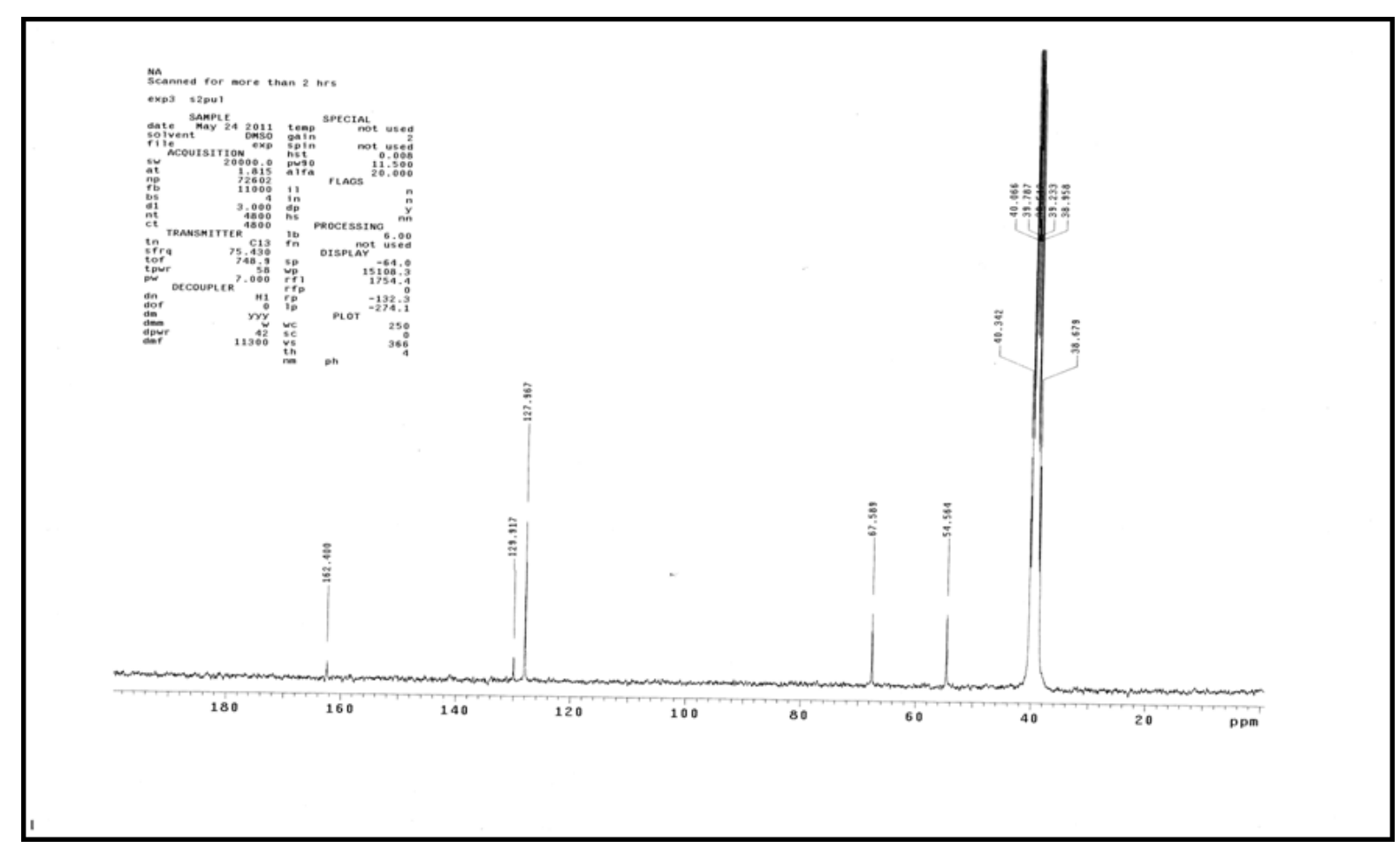

Fig. 4: ${ }^{13} \mathrm{C}-\mathrm{NMR}$ spectrum of $\mathrm{PBO}$

\section{Mass spectral analysis}

The mass spectrum shows peak at m/e 251.13 with intensity almost $100 \%$ relating to molecular weight of BHETA Fig. 5 (a), where as intense peak at m/e 217.19 was attributed to molecular weight of PBO Fig 5 (b). 


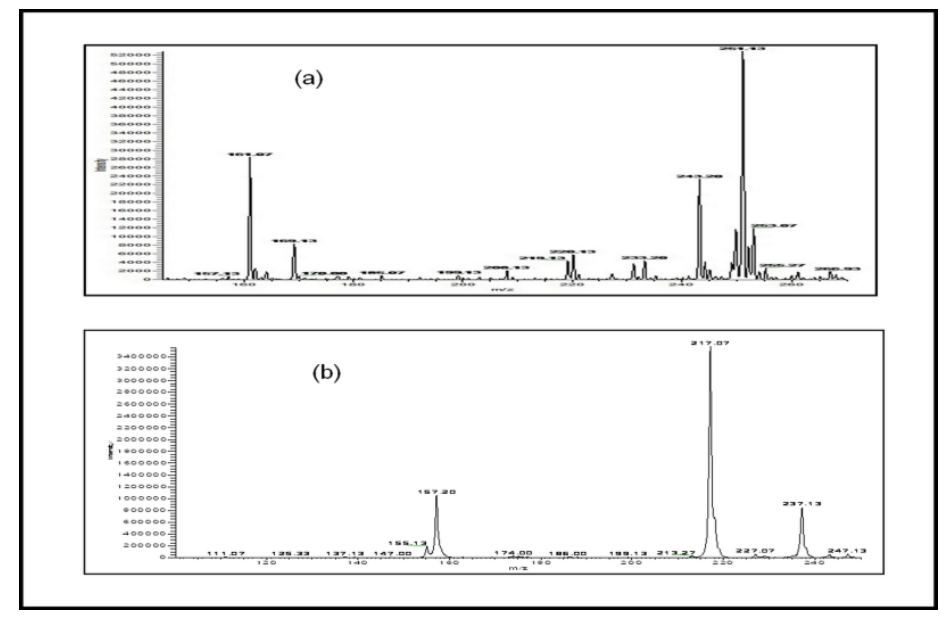

Fig. 5. Mass spectra of (a) BHETA and (b) PBO

\section{References}

1. Kawabata N. (1999) Recycle for Polymers. Polymeric Materials Premised for Recycled Use Kobunshi (in Japanese). 48, 774-777.

2. Paszun D., and Spychaj T. (1997) Chemical Recycling of Poly (ethylene terephthalate). Ind Eng Chem Res. 36, 1373-1383.

3. Spychaj T., and Paszun D. (1975) Method of chemically degrading poly (ethylene terephthalate). Pol. Pat. 179018.

4. Soni R. K., and Singh S. (2005) Synthesis and characterization of terephthalamides from poly (ethylene terephthalate) waste. J. Appl. Polym. Sci. 96, 1515-1528.

5. Goje A. S., Thakur S. A., Diware V. R., Chauhan Y. P., and Mishra S. (2004) Synthesis and characterization of terephthalamides from poly (ethylene terephthalate) waste. Polym. Plast. Technol. Eng. 43, 407-426.

6. Fabrycy E., A. Leistner and T. Spychaj. (2000) New epoxy resin hardeners from PET scrap. Adhesion. 44, 35-39.

7. Spychaj T., Fabrycy E. A., and Spychaj S. (2001) Aminolysis and aminoglycolysis of waste poly (ethylene terephthalate). J. Mater. Cycles. Waste. Manage. 3, 24-31.

8. Shukla S. R., and Harad A. M. (2006) Aminolysis of polyethylene terephthalate waste. Polym. Degrad. Stab. 91, 1850-1854.

9. Shukla S. R., and Pingale N. D. (2009) Microwave-assisted aminolytic depolymerization of PET waste. Eur. Polym. J. 45, 2695-2700.

10. (a) Marvi O., and Giahi M (2009) Montmorillonite KSF Clay as Novel and Recyclable Heterogeneous Catalyst for the Microwave Mediated Synthesis of Indan-1,3-diones. Bull. Korean. Chem. Soc. 30, 2918-2920.

10. (b) Nikpassand M., Mamaghani M., and Tabatabaeian K. (2009) An Efficient Catalyst for the Regioselective Synthesis of 1,5-Diaryl Pyrazoles Using BaylisHillman adducts. Mol. Divers. 13, 389-393.

10. (c) Neji S. B., Trabelsi M., and Frikha M. H. (2009) Esterification of Fatty Acids with ShortChain Alcohols over Commercial Acid Clays in a Semi-Continuous Reactor. Energies 2, 1107-1117.

11. Scherzer J. (1989) Octane-Enhancing, Zeolitic FCC Catalysts: Scientific and Technical Aspects. Catal. Rev. - Sci. Eng. 31, 215-354.

12. Haruo O., Hironobu S., Akira I., and Yusuke Y. (2007) Acylation of amines by aminolysis of esters over H-ZSM-5 catalyat. Bull. of Tokyo Gakugei University, Natural Science 59, 19-25

13. Caddick S. (1995) Microwave-assisted organic reactions Tetrahedron. 51, 10403-10432. 
14. Lidstrom P., Tierney J., Wathey, B., and Westman J. (2001) Microwave assisted organic synthesis - a review. Tetrahedron 57, 9225-9283.

15. Krstic L. J., Sukdolak S., and Solujic S. (2002) An efficient synthesis of warfarin acetals on montmorillonite clay K-10 with microwaves. J. Serb. Chem. Soc. 67, 325-329.

16. Culbertson B., and Tiba O. (1989) Liquid aromatic bisoxazoline and bisoxazine monomer mixtures and process for crosslinking using phenolics. US. Pat.4806267.

17. Culbertson B. M. (2002) Cyclic imino ethers in step-growth polymerizations. Prog. Polym. Sci. 27, 579-626.

18. Benthem V., Loontjens J. and Hendriks P. (2002) Preparation of an aromatic bisoxazoline. US. Pat.0091203.

19. Kubelbaeck T., Neumann M. and Omels M. (2010) Process for preparing heterocycles. US. Pat. 0076186.

20. Witte H., and Seeliger W. (1974) Simple synthesis of 2-substituted 2-oxazolines and 5,6dihydro-4H-1 ... of nitriles with amino alcohols. Justus. Liebigs. Ann. Chem. 6, 996-1009.

21. Witte H., and Seeliger W. (1972) Simple synthesis of 2-substituted 2- oxazolines and 5, 6dihydro- 4H- 1, 3- oxazines. Angew. Chem. Int. Ed. Engl. 11, 287-289.

22. Benicewicz B., Mitchell M., and Mex N. (1995) Synthesis of oxazolines and oxazines. US. Pat. 5382665.

23. Laurent N., Lefebvre H., and Fradet A. (2003) Kinetic and Mechanistic Studies of Carboxylic Acid-Bisoxazoline Chain-Coupling Reactions Macromol. Chem. Phys. 204, 1755-1764.

24. Po R., Abis L., Fiocca L., and Mansani R. (1995) Synthesis and Characterization of Poly (Ester-Amide)S from bis(2-Oxazoline)S, Anhydrides, and Diols. Macromolecules. 28, 56995705.

25. Van b. (2003) Preparation of an aromatic bisoxazoline. US. Pat. 6660869.

26. Benicewicz. (1995) Synthesis of oxazolines and oxazines. US. Pat. 5382665.

27. Wenker H. (1935) The Synthesis of 2-Oxazolines and 2-Thiazolines from N-Acyl-2aminoethanols. J. Am. Chem. Soc. 57, 1079-1080.

28. Vorbru H., and Krolikiewicz K. (1981) A simple synthesis of $\Delta 2$-oxazolines, $\Delta 2$-oxazines, $\Delta 2$ thiazolines and $\Delta 2$-imidazolines. Tetrahedron Lett. 22, 4471-4474.

29. Cwik A., Hell Z., Hegedu A., Finta Z., and Horva Z. (2002) A simple synthesis of 2substituted oxazolines and oxazines. Tetrahedron Lett. 43, 3985-3987.

30. Marrero-Terrero A. L., and Loupy A. (1996) Synthesis of 2-Oxazolines from Carboxylic Acids and $\alpha, \alpha, \alpha$-Tris (hydroxymethyl) methylamine under Microwaves in Solvent-Free Conditions. Synlett 3, 245-246.

31. Frump J. A., (1971) Oxazolines. Their preparation, reactions, and applications. Chem. Rev. 71, 483-505.

32. Lion C., and Dubois J. E. (1973) Synthese de cetones aliphatiques encombrees : Action des organolithiens sur les dimethyl-4,4 oxazolines-2. Addition des organometalliques sur les sels de dimethyl-4,4 oxazolinium-2. Tetrahedron 29, 3417-3423.

33. Bolm C., Weickhardt K., Zehnder M., and Ranff T. (1991) Synthesis of Optically Active Bis(2-oxazolines): Crystal Structure of a 1,2-Bis(2-oxazolinyl)benzene ZnCl2 Complex. Chem. Ber. 124, 1173-1180.

34. Lafargue P., Guenot P., and Lellouche J. P. (1995) Preparation of 2-thiazolines from $(1,2)-$ thioamido-alcohols. DAST as a useful reagent. Synlett 2, 171-172.

35. Mahler S. G., Serra G. L., Antonow D., and Manta E. (2001) Deoxo-Fluor-mediated cyclodehydration of $\beta$-hydroxy thioamides to the corresponding thiazolines. Tetrahedron Lett. 42, 8143-8146.

36. Bandgar B. P., and Pandit S. S. (2003) Direct synthesis of 2-oxazolines from carboxylic acids using 2- chloro-4, 6-dimethoxy-1,3,5-triazine under mild conditions. Tetrahedron Lett. 44, 2331-2333.

37. Shukla S. R., and Pingale N. D. (2008) Microwave assisted ecofriendly recycling of poly (ethylene terephthalate) bottle waste. Eur. Polym. J. 44, 4151-4156. 